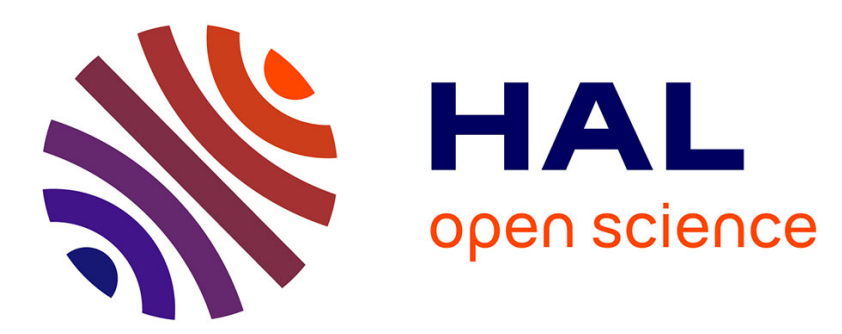

\title{
Effect of Inclined Wavy Surface on Heat Transfer inside a Rectangular Cavity: Solar Applications
}

\author{
Y. Agrouaz, T. Bouhal, A. Jamil, A.A. Msaad, Tarik Kousksou, M. \\ Mahdaoui, T.E. Rhafiki
}

\section{- To cite this version:}

Y. Agrouaz, T. Bouhal, A. Jamil, A.A. Msaad, Tarik Kousksou, et al.. Effect of Inclined Wavy Surface on Heat Transfer inside a Rectangular Cavity: Solar Applications. IEEE International Renewable and Sustainable Energy Conference, IRSEC 2015, Dec 2015, Marrakech, Morocco. pp.1-6, 10.1109/IRSEC.2015.7455006 . hal-02153995

\section{HAL Id: hal-02153995 \\ https: / hal-univ-pau.archives-ouvertes.fr/hal-02153995}

Submitted on 8 Oct 2020

HAL is a multi-disciplinary open access archive for the deposit and dissemination of scientific research documents, whether they are published or not. The documents may come from teaching and research institutions in France or abroad, or from public or private research centers.
L'archive ouverte pluridisciplinaire HAL, est destinée au dépôt et à la diffusion de documents scientifiques de niveau recherche, publiés ou non, émanant des établissements d'enseignement et de recherche français ou étrangers, des laboratoires publics ou privés.

\section{(c)(1)}

Distributed under a Creative Commons Attribution| 4.0 International License 


\section{Effect of inclined Wavy Surface on Heat Transfer Inside a Rectangular Cavity: Solar Applications}

\author{
Younes Agrouaz*, Tarik Bouhal, Abdelmajid Jamil, \\ Abdelouahad Ait Msaad \\ Université Sidi Mohamed Ibn Abdelah \\ Ecole Supérieure des Technologies, EST \\ Fès, Morocco \\ agrouazyounes@Gmail.com
}

\author{
Tarik Kousksou, Mustapha Mahdaoui \\ Laboratoire des Sciences de l'Ingénieur Appliquées \\ à la Mécanique et au Génie Electrique (SIAME) \\ Université de Pau et des Pays de l'Adour \\ Pau, France \\ Tarik El Rhafiki \\ Université Moualy Ismail \\ Ecole Nationale Supérieure d'Arts et Métiers, ENSAM \\ Meknès, Morocco
}

\begin{abstract}
In this present work a steady-state natural convection was numerically simulated in an inclined rectangular cavity with a sinusoidal bottom wavy wall. The vertical walls are insulated while the bottom surface maintained to higher temperature than the top surface. In this numerical simulation, Rayleigh number $\left(10^{3}, 10^{6}\right.$ and $\left.6 \times 10^{6}\right)$ and inclination angle $\left(30^{\circ}, 60^{\circ}\right.$ and $\left.90^{\circ}\right)$ were chosen in order to analyze the effect of these parameters on the heat transfer and the flow fields in two dimensional(2-D) enclosure filled in air $(\operatorname{Pr}=0.71)$. It is found that the same Rayleigh number,the heat transfer is influenced by the inclination angle. In other words the increase of inclination angle leads to an increase in the heat transfer inside the rectangular cavity.
\end{abstract}

Keywords-natural convection; numerical simulation; heat transfer.

\section{INTRODUCTION}

Natural convection flow and heat transfer characteristics in a rectangular cavities have received an important attention in the past decades. This importance due to its thermal performances in several applications such as cooling of electronic devices, food processing, drying technologies, solar collectors, energy storage systems, cooling technologies [1-2].

In a cavity, when the two vertical walls are differentially heated and the top and bottom walls are maintained under adiabatic conditions. The density gradient (due to temperature gradient) is horizontal and the gravity vector acts perpendicularly. These two vectors act normal to each other and the direction of the circulation depends upon their orientation. However, the situation becomes more complex when these two vectors are parallel to each other. When the bottom wall is heated and the top wall is cooled, the density increases from bottom to top.

These two vectors are parallel and opposite to each other. In this case the circulation will start after a critical Rayleigh number is reached [3]. The literature have widely studied a natural convection in an enclosures for square, rectangular and inclined walled geometries, but there is a limited number of studies with wavy inclined walled enclosures due to the complexity of the fluid hydrodynamics inside the cavity. The complexity of this physical phenomena is a consequence of the geometry and the boundaries conditions. For example Amaresh and Manab [4] have given a parametric study of the influence of Rayleigh number, amplitude of undulation and number of undulations on the flow and the heat transfer inside the cavity. Catton [5] and Yang [6] have shown the advantage of inclined cavities on the thermal behavior of the flow regimes. On the other hand Yasin and Oztop [7] studied numerically a natural convection heat transfer in a horizontal and wavy enclosure. They showed that the heat transfer is increased with the decreasing non-dimensional wave length and Rayleigh number.

In this paper, the main objective is to extend our comprehension to the laminar natural convection in a rectangular cavity having three flat walls and the bottom wall consisting of three undulations of amplitude 0.10 . The two vertical walls are maintained adiabatic and the top wall are maintained at a fixed lower temperature than the sinusoidal bottom wall.

\section{PHYSICAL MODEL AND GOVERNING EQUATIONS}

\section{A. Description of schematic model}

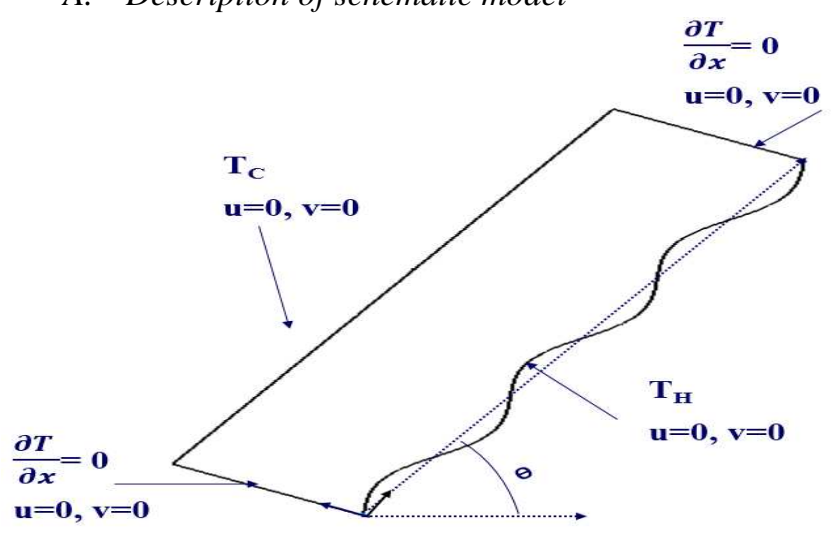

Figure.1 The description of the geometrical configuration 


\section{NOMENCLATURE}

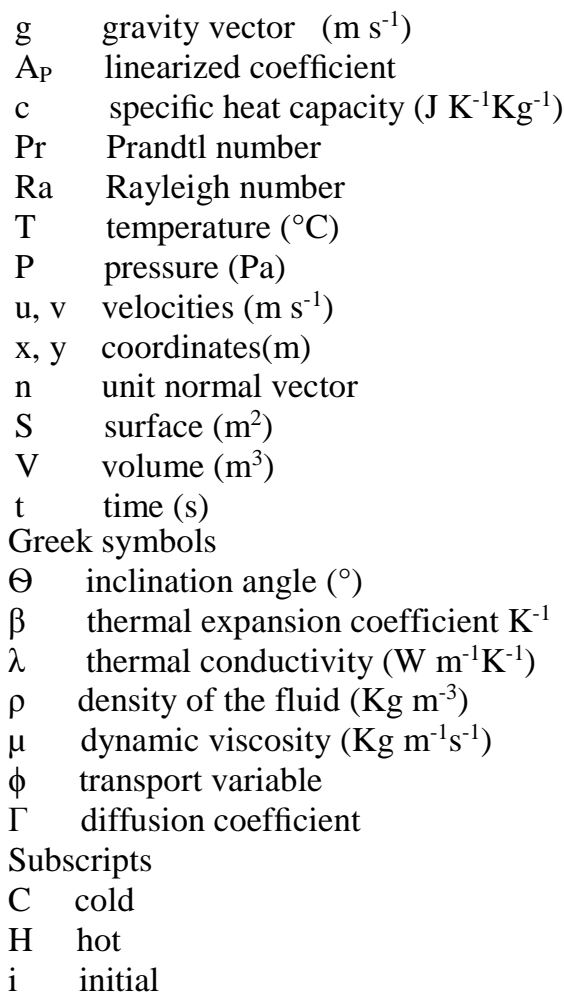

The schematic configuration of a wavy inclined wall is given in Fig. 1.The boundaries condition are also plotted on this figure showing that inclined adiabatic wall. The cold and hot wall correspond respectively to the top and bottom of the cavity. The geometrical characteristic such as wave length, height and width are also depicted on Fig.1.

\section{B. Mathematical model}

The following assumptions are made in the analysis

- The Boussinesq approximation is valid, i.e., liquid density variations arise only in the buoyancy source term, but are otherwise neglected.

o The air is Newtonian.

- Viscous dissipation is neglected.

- Fluid motion in the melt is laminar and two-dimensional.

With the foregoing assumptions, the conservation equations for mass, momentum and energy may be stated as

$$
\begin{gathered}
\int_{S} \vec{u} \cdot \vec{n} d S=0 \\
\frac{d}{d t} \int_{V} \rho \vec{u} d V+\int_{S} \rho \vec{u} \vec{u} . \vec{n} d S=-\int_{V} \vec{\nabla} p d V+\int_{S} \overline{\bar{\tau}} \cdot \vec{n} d S+\int_{V} \vec{A} U
\end{gathered}
$$

$$
\frac{d}{d t} \int_{V} \rho c_{p} T d V+\int_{S} \rho c_{p} T \vec{u} \cdot \vec{n} d S=\int_{S} \lambda \vec{\nabla} T \cdot \vec{n} d S
$$

Where $\vec{u}$ is the velocity vector, $p$ the pressure and $T$ the temperature. $\overline{\bar{\tau}}$ is the viscous stress tensor for a Newtonian fluid:

$$
\overline{\bar{\tau}}=\mu\left(\overline{\bar{\nabla}} u+(\overline{\bar{\nabla}} u)^{T}\right)
$$

The integration occurs over a control volume (CV) surrounded by a surface $S$, which is oriented by an outward unit normal vector $\vec{n}$. The source term in Eq. (2) contains two parts:

$$
\vec{A}_{U}=\rho \beta\left(T-T_{m}\right) \vec{g}
$$

where $\beta$ is the coefficient of volumetric thermal expansion and $\vec{g}$ the acceleration of gravity vector. The first part of the term source represents the buoyancy forces due to the thermal dilatation. $T_{m}$ is the reference temperature.

\section{NUMERICAL SCHEME}

The conservation Eqs.1-3 are solved by implementing them in an in house code. This code has been successfully validated in several situations involving flow and heat transfer as in [8-9]. The present code has a two dimensional unstructured finitevolume framework that is applied to hybrid meshes. The variables values are stored in cell centers in a collocated arrangement. All the conservation equations have the same general form. By taking into account the shape of control volumes, the representative conservation equation to be discretized may be written as

$$
\frac{d}{d t} \int_{V} \rho \phi d V+\sum_{i} \int_{S_{j}}\left[\rho u_{i} \phi-\Gamma_{\phi} \frac{\partial \phi}{\partial x_{i}}\right] d S_{i}=\int_{V} S_{\phi} d V
$$

generally,this convective phenomena, where the explicit schemes are too restrictive owing to stability limitations. Hence implicit schemes are often preferred and the simplest choice is the first order Euler scheme. The cell face values, appearing in the convective fluxes, were obtained by blending the upwind differencing scheme (UDS) and the central difference scheme (CDS) using the differed correction approach [10-11]. The coupling of the dependent variables was obtained on the basis of the iterative SIMPLE algorithm developed by Patankar and Spalding [12-13].

Summation of the fluxes through all the faces of a given CV results in an algebraic equation which links the value of the dependent variable at the $\mathrm{CV}$ centre with the neighbouring values. The equation may also be written in a conventional manner as 


$$
A_{P} \phi_{P}=\sum_{n b} A_{n b} \phi_{n b}+b_{\phi}
$$

The coefficients $A_{n b}$ contain contributions of the neighboring (nb) CVs, arising out of convection and diffusion fluxes as defined by Eqs. (1)-(3). The central coefficient $A_{P}$ on the other hand, includes the contributions from all the neighbours and the transient term. In some of the cases, where sources term linearization was applied, it also contained part of the source terms. $b_{\phi}$ contains all the terms those are treated as known (source terms, differed corrections and part of the unsteady term).

The momentum, pressure correction and temperature are solved sequentially using an ILU-preconditioned GMRES procedure implemented in the IML++ library [14]. All of the computational meshes were generated using the open-source software Gmsh [15].

\section{RESULT AND DISCUSSION}

A numerical simulation is made to study the effect of wavy inclined wall on natural convection flow and heat transfer inside the rectangular cavity. Various studies investigated [16] flow and heat transfer inside inclined cavities for different Rayleigh number Ra. In this study the effect of the Rayleigh number and the inclination angles on the flow and inside the cavity is presented.

The effective Parameters on natural convection are the Rayleigh number which changes between $10^{3}$ and $6 \times 10^{6}$ and the inclination angle which changes from $30^{\circ}$ to $90^{\circ}$. Prandtl number is taken as fixed as 0.71 which corresponds to air.
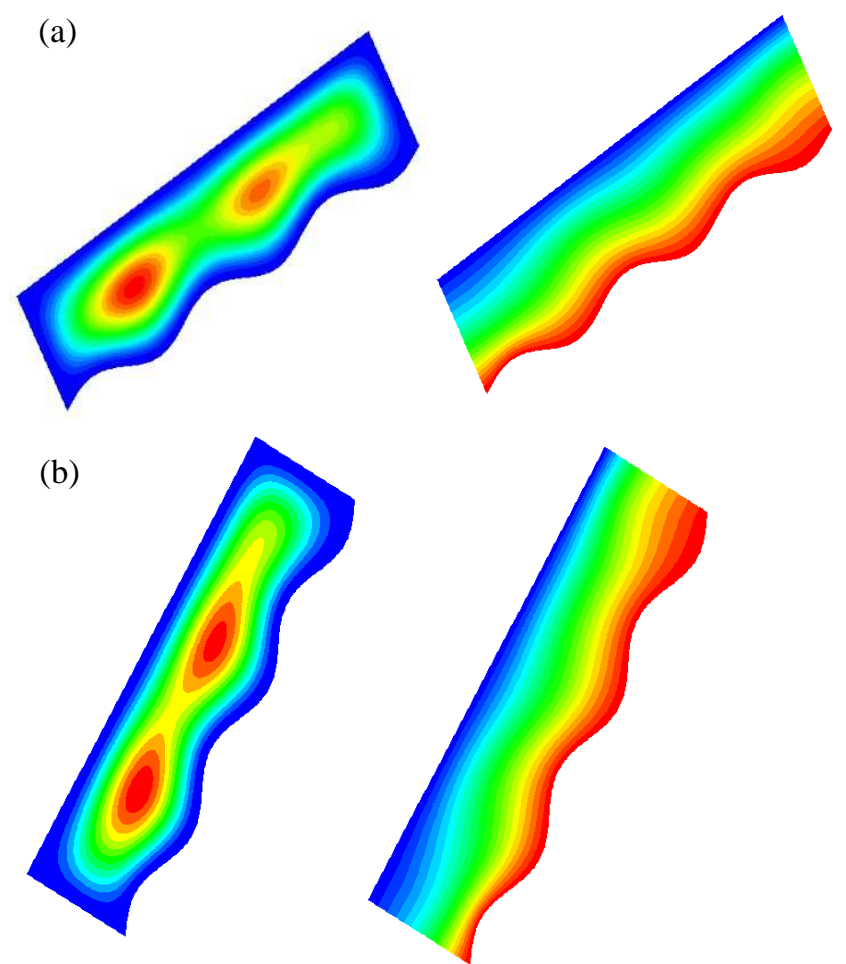

(c)

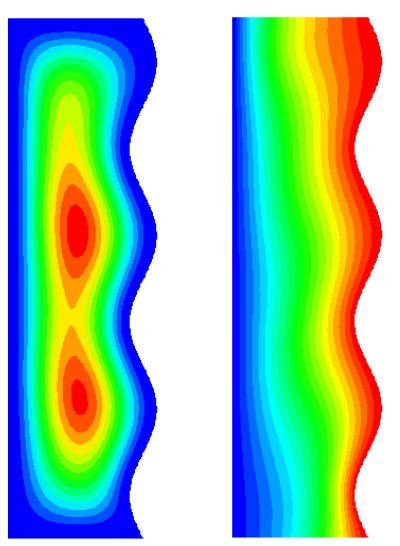

Figure. 2 The stream function and isotherms at $\mathrm{Ra}=10^{3}$ : (a) $\Theta=30^{\circ}$, (b) $\Theta=60^{\circ}$, (c) $\Theta=90^{\circ}$.

The effects of inclination angles are presented in Fig. 2 with streamlines and isotherms. It is clearly seen that the main two cells are obtained in the middle of the cavity.

When the inclination angle is increased the two cells are moved to each other. This movement is due to value of the gravitation component affected by the inclination angles. Isotherms show plume-like shape from bottom to top. They acted as differentially heated cavity.

While increasing Rayleigh number from $10^{6}$ to $6 \times 10^{6}$ respectively in Fig. 3 and Fig. 4. It is obviously noted that movement of the two cells is accelerated to develop a single main cell at $\Theta=90^{\circ}$.

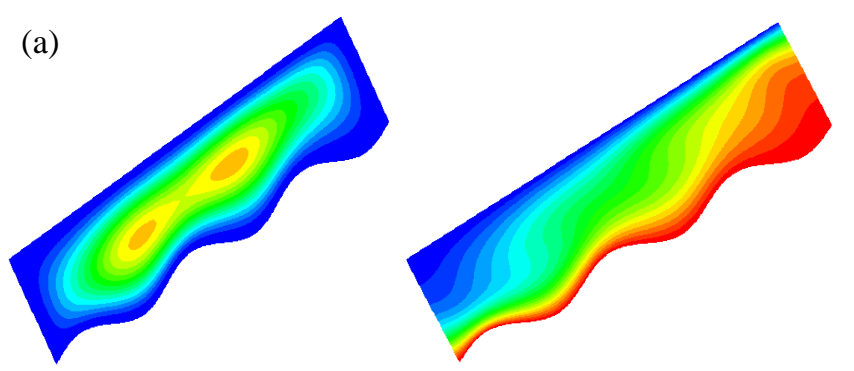

(b)

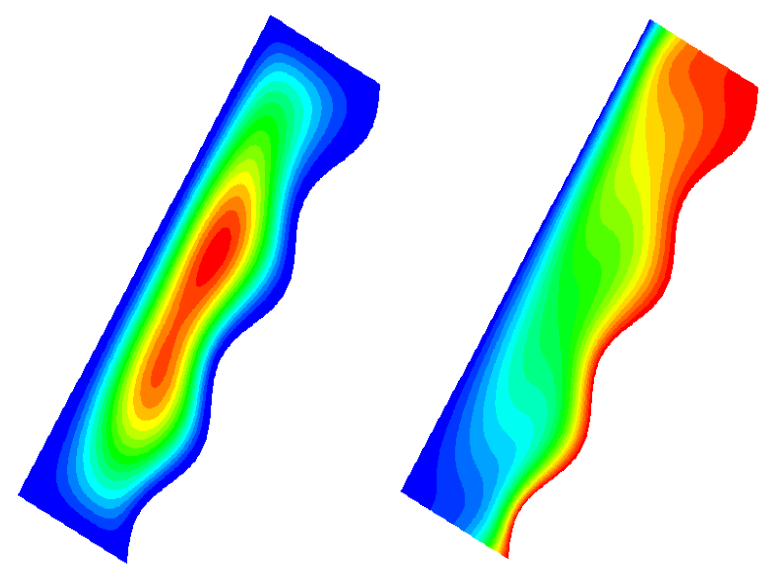


(c)
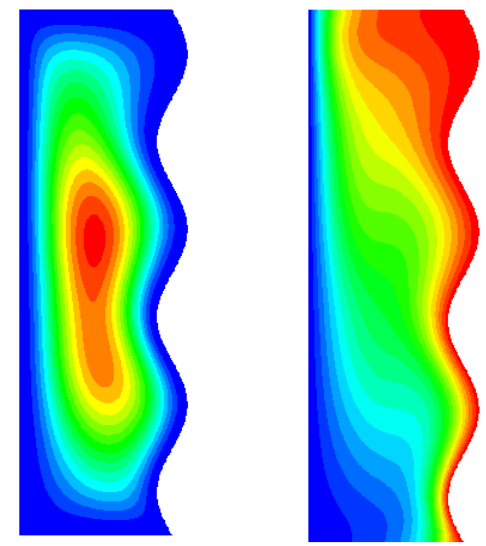

Figure. 3 The stream function and isotherms at $\mathrm{Ra}=10^{6}$ : (a) $\Theta=30^{\circ}$, (b) $\Theta=60^{\circ}$, (c) $\Theta=90^{\circ}$.

The change from multiple cells to a single cell expand the heat transfer inside the enclosure. The comparison between the Fig.2, Fig.3 and Fig.4 show isotherms that are highly concentrated on the hot wall. Heated fluid moves up to the top of the cavity and the flow which encroached on to the upper surface turns to the left and right.

The revise of this isotherms from a thermal point of view exhibit an important enhancement on the distribution of the temperature, which occurs inside the wavy enclosure. It is evident that both flow and temperature differences are influenced by the inclination angles of the enclosure at the same Rayleigh number.

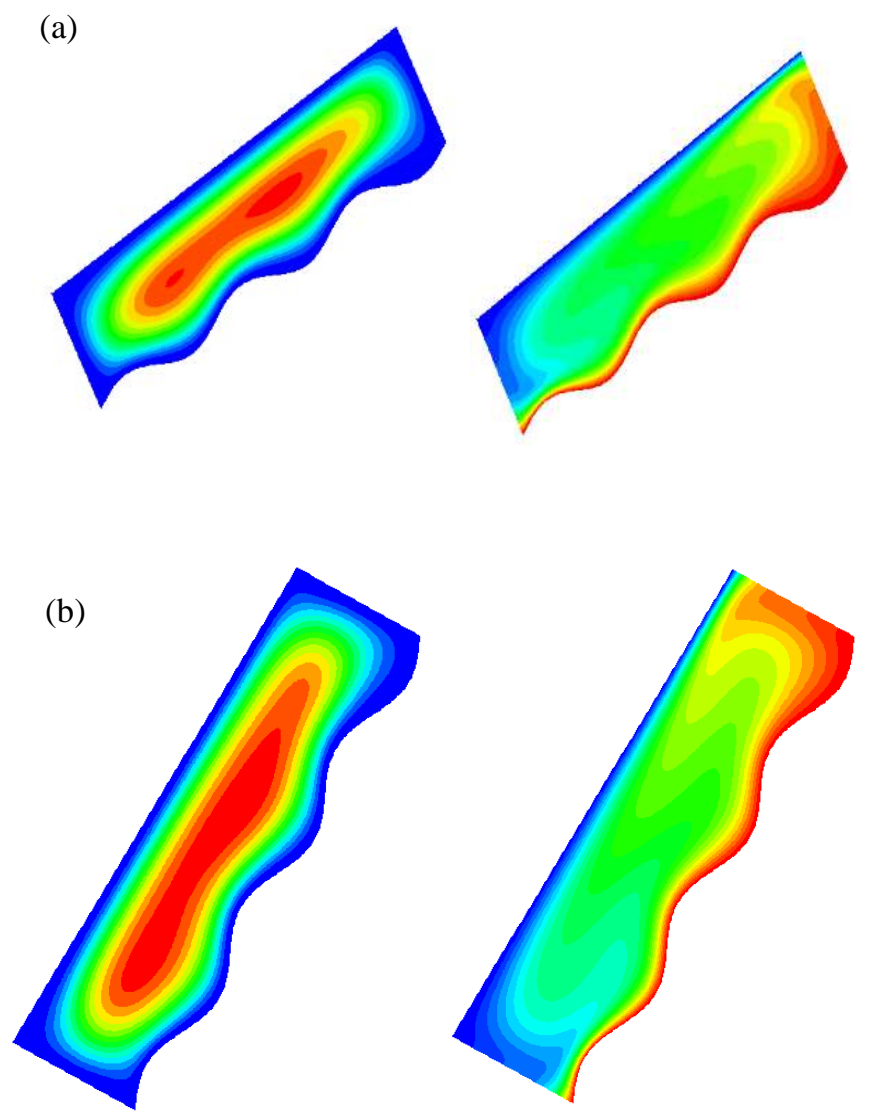

(c)
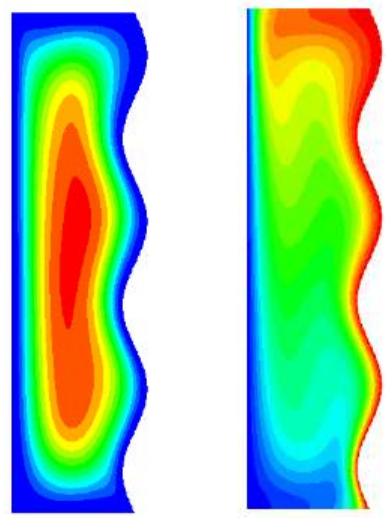

Figure. 4 The stream function and isotherms at $\mathrm{Ra}=6 \times 10^{6}$ : (a) $\Theta=30^{\circ}$, (b) $\Theta=60^{\circ}$, (c) $\Theta=90^{\circ}$.

Fig.5, Fig.6 and Fig.7 define the variation of local Nusselt number along the wavy wall with different inclination angles at different value of Rayleigh number. The mode of the local Nusselt number is wavy as indicated by Dalal and Das [17]. It is clearly seen that nusselt number increases with an increase in Rayleigh number for all the inclination angles.

Fig.5 represents the value of nusselt number at $\mathrm{Ra}=10^{3}$ for $\theta=30^{\circ}, \theta=60^{\circ}, \theta=90^{\circ}$ which proves the patterns of the isotherms and the stream function as shown in Fig.1.

It has peak value on the top of each wave and their value is almost the same for different inclination angles except the right hill of the wavy inclined bottom surface, it dues to the adiabatic boundaries that influences the temperature distribution in the cavity.

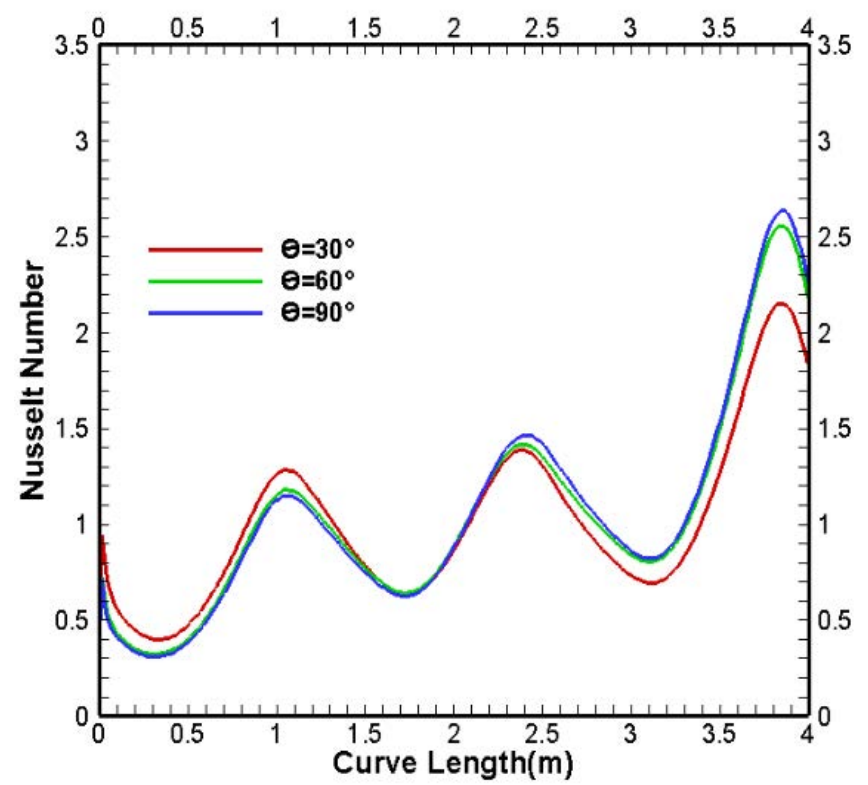

Figure. 5 The nusselt number of the hot wavy surface at $\mathrm{Ra}=10^{3}$ 


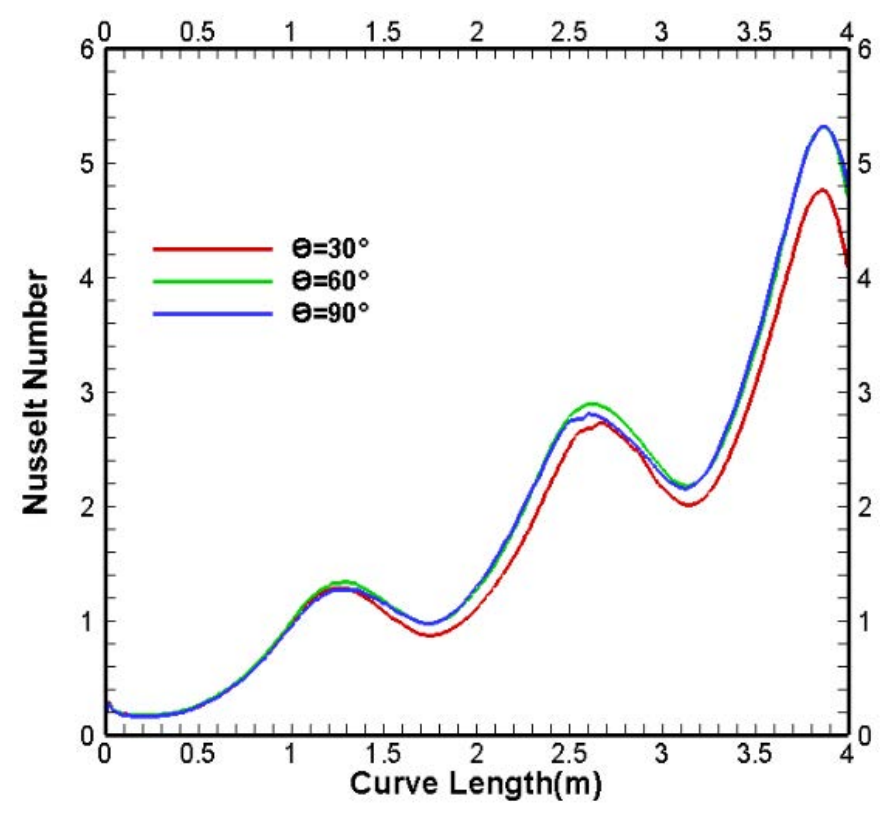

Figure.6 The nusselt number of the hot wavy surface at $\mathrm{Ra}=10^{6}$

As expected, Rayleigh number enhances the Nusselt number. The highest Nusselt number is obtained for $\Theta=90^{\circ}$, however, the smallest Nusselt number is formed at $\Theta=30^{\circ}$, interestingly. When the values of $\mathrm{Ra}=6 \times 10^{6}$, the value of nusselt number decreases for the higher angles.

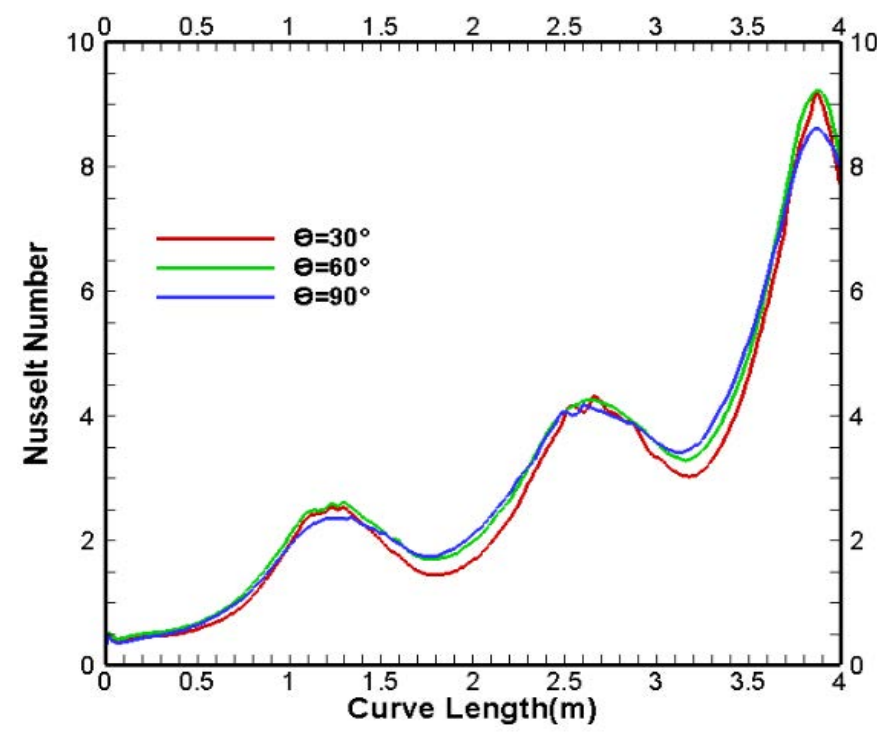

Figure.7 The nusselt number of the hot wavy surface at $\mathrm{Ra}=6 \times 10^{6}$

\section{CONCLUSION}

A numerical investigation is carried out on natural convection heat transfer inside a rectangular wavy inclined cavity. This study shows the influence of the governing parameters (Rayleigh number and the inclination angle) at same amplitude and wave length of the sinusoidal bottom wall. A thermal analysis is performed to determine the optimal angle that present a higher nusselt number (heat transfer) in order to give designers, manufacturers and researchers an effective configuration for different application such as a shape of solar collector, thermal exchangers.

The main results can be cited as follows:

1. Nusselt number increases with Rayleigh number at same angle of inclination.

2. At same Rayleigh number, there is an enhancement on nusselt number when the angle of inclination augment.

3. The importance of the gravitational component on the distribution of the temperature inside the cavity.

\section{ACKNOWLEDGMENT}

The authors wish to give special gratitude to the academic and the financial support provided by the «Institut de Recherche en Energie Solaire et Energies Nouvelles (IRESEN) » under the project of Solar Cooling Process in Morocco (SCPM).

\section{REFERENCES}

[1] M. Aounallah, Y. Addad, S. Benhamadouche, O. Imine, L. Adjlout and D. Laurence, "Numerical investigation of turbulent natural convection in an inclined square cavity with a hot wavy wall", International Journal of Heat and Mass Transfer, vol. 50, no. 9-10, pp. 1683-1693, 2007.

[2] F. Zemani, A. Sabeur-Bendehina and M. Boussoufi, "Numerical Investigation of Natural Convection in Air Filled Cubical Enclosure with Hot Wavy Surface and Partial Partitions", Procedia Computer Science, vol. 32, pp. 622-630, 2014.

[3] A. Dalal and M. Das, "Numerical study of laminar natural convection in a complicated cavity heated from top with sinusoidal temperature and cooled from other sides", Computers \& Fluids, vol. 36, no. 4, pp. 680$700,2007$.

[4] A. Dalal and M. Das, "Heatline method for the visualization of natural convection in a complicated cavity", International Journal of Heat and Mass Transfer, vol. 51, no. 1-2, pp. 263-272, 2008.

[5] S. Rhee, V. Dhir and I. Catton, "Natural Convection Heat Transfer in Beds of Inductively Heated Particles", J. Heat Transfer, vol. 100, no. 1, p. 78,1978 .

[6] K. Yang, "Transitions and Bifurcations in Laminar Buoyant Flows in Confined Enclosures", J. Heat Transfer, vol. 110, no. 4, p. 1191, 1988.

[7] Y. Varol and H. Oztop, "Free convection in a shallow wavy enclosure", International Communications in Heat and Mass Transfer, vol. 33, no. 6, pp. 764-771, 2006.

[8] T. Kousksou, M. Mahdaoui, A. Ahmed and A. Msaad, "Melting over a wavy surface in a rectangular cavity heated from below", Energy, vol. 64, pp. 212-219, 2014.

[9] A. Arid, T. Kousksou, S. Jegadheeswaran, A. Jamil, Y. Zeraouli, Numerical simulation of ice Melting near the density inversion point under periodic thermal boundary conditions, Fluid Dynamics Materials Processing 305 (2012) 1-19. 
[10] P. Khosla and S. Rubin, "A diagonally dominant second-order accurate implicit scheme", Computers \& Fluids, vol. 2, no. 2, pp. 207-209, 1974.

[11] S. Jana, S. Ray and F. Durst, "A numerical method to compute solidification and melting processes", Applied Mathematical Modelling, vol. 31, no. 1, pp. 93-119, 2007.

[12] S.V. Patankar, Numerical Heat Transfer and Fluid Flow. Hemisphere, Washington DC, 1980.

[13] S.V. Patankar, D.B. Spalding, A calculation of heat, mass and momentum transfer in three dimensional parabolic flows, Int. J. Heat Mass Transfer 15 (1972)1787-1806.

[14] J. Dongarra, A. Lumsdaine, R. Pozo, K. Remington, A sparse matrix library in $\mathrm{C}++$ for high performance architectures, in : Proceedings of the Second Object Oriented Numerics Conference (1994) 214-218.

[15] C. Geuzaine, J.F. Remacle, Gmsh: a three dimensional finite element mesh generator with built in pre and post processing facilities.International Journal for Numerical Methods in Engineering 79 (2009) 1309-1331.

[16] K. Hollands and L. Konicek, "Experimental study of the stability of differentially heated inclined air layers", International Journal of Heat and Mass Transfer, vol. 16, no. 7, pp. 1467-1476, 1973

[17] A. Dalal and M. Das, "Natural Convection in a Cavity With a Wavy Wall Heated From Below and Uniformly Cooled From the Top and Both Sides", J. Heat Transfer, vol. 128, no. 7, p. 717, 2006 